\title{
Prolonged Survival in a Patient with Neuroendocrine Tumor of the Cecum and Diffuse Peritoneal Carcinomatosis
}

\author{
Louis de Mestier $^{\mathrm{a}}$ Cindy Neuzillet ${ }^{\mathrm{a}}$ Olivia Hentic $^{\mathrm{a}}$ \\ Reza Kianmanesh $^{\mathrm{b}}$ Pascal Hammel ${ }^{\mathrm{a}}$ Philippe Ruszniewski ${ }^{\mathrm{a}}$

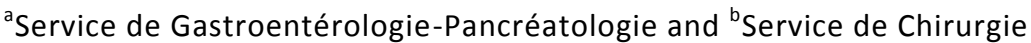 \\ Hépato-Biliaire, Pôle des Maladies de l'Appareil Digestif, Hôpital Beaujon \\ (AP-HP and Université Paris VII - Denis Diderot), Clichy, France
}

\section{Key Words}

Digestive neuroendocrine tumors - Dissemination - Peritoneal carcinomatosis .

Prognosis · Survival

\begin{abstract}
Peritoneal carcinomatosis is a well-known factor of poor prognosis in patients with digestive adenocarcinomas. Peritoneal dissemination may also occur in midgut well-differentiated neuroendocrine tumors, but its influence on survival is ill-defined. We report here the history of a 64-year-old woman who had a neuroendocrine tumor of the cecum with multiple synchronous metastases in the liver and diffuse peritoneal carcinomatosis. She underwent surgical resection of the primary tumor and cytoreduction of liver metastases, and received subsequently chemotherapy and somatostatin analogs. In spite of the widespread extension of the disease, she survived for 13 years and died from a carcinoid heart disease. We discuss the natural history and prognostic factors in patients with midgut well-differentiated neuroendocrine tumors, with a focus on the impact of the peritoneal carcinomatosis.
\end{abstract}

\section{Introduction}

Well-differentiated digestive neuroendocrine tumors (NETs) of midgut origin are usually of slow course. Mean global survival is 6.6 years, and the 5 -year survival rate exceeds $60 \%$ when pooling all stages [1-4]. Poor prognostic factors have been well identified [3-6]: male gender, age $>50$ years, jejuno-ileal localization, tumor size $\geq 2 \mathrm{~cm}$, tumor depth (ENETS [7] and UICC staging [8]), presence of symptoms upon discovery 
(such as carcinoid syndrome) and distant metastases. Depending on the presence or absence of metastases, 5-year survival rates are respectively of 47 and $73 \%[1,4]$. The Ki67 proliferation index is a major element of the 2010 WHO classification of digestive NETs $[7,9]$, and other histological prognostic factors are vascular invasion and presence of necrosis. Multiplicity of primitive tumors seems also to be predictive of a distant spreading and poor prognosis [10]. Some studies have suggested that a high level of hormonal secretion is a pejorative factor [4]. The prognosis of these patients might also be influenced by the occurrence of other syndromes or metachronous cancers (colorectal, bladder, endometrial or ovarian carcinomas) that occur in 22 or $10 \%$ of patients, respectively [3]. Finally, survival is influenced by the risk of terminal right heart failure due to carcinoid tricuspid valve insufficiency depending on the degree of metastatic involvement of the liver.

We report here a case of prolonged survival in a patient who had a welldifferentiated NET of the midgut with peritoneal dissemination, and discuss the prognostic impact of peritoneal carcinomatosis (PC) in NETs.

\section{Case Report}

A 64-year-old woman was referred to our institution in September 1991 for abdominal pain located in the right hypochondrium and nausea without any other symptom. Abdominal ultrasound followed by CT scan showed three nodular lesions in the left liver lobe, measuring $3 \mathrm{~cm}$ in diameter. A percutaneous biopsy was performed and histological analysis showed a well-differentiated NET. Upper gastrointestinal endoscopy was normal. Colonoscopy showed a large occlusive tumor whose biopsies were identical to the liver tumor. Urinary 5HIAA was four times the upper limit value of normal $(\mathrm{N})$.

A laparoscopy was performed in October 1991. The exploration found bilobar liver metastases and a diffuse PC consisting of hundreds of nodules (the largest $>3 \mathrm{~cm}$ in diameter), corresponding to unresectable stage IV carcinomatosis according to Gilly's classification. The ileocolic region and the right colon were resected, and cytoreductive surgery of the metastases located in left liver was performed, consisting in a partial left hepatectomy. Histopathological examination of the resected segment of the bowel showed multiple well-differentiated NETs, with Ki67 at 12\%. The largest bowel tumor measured $30 \mathrm{~mm}$ in diameter and was located $1 \mathrm{~cm}$ above to the ileocolic valve, with invasion of the visceral peritoneum (T4 according to ENETS-TNM [7] or UICC-TNM [8] staging, and G2 according to WHO grading $[7,9])$. Three other smaller and less infiltrative tumors $(5-10 \mathrm{~mm}$ in diameter) were found at the appendix base. Pathological analysis confirmed the diffuse both macroscopical and microscopical PC. Examination of the liver resection specimen showed multiple metastases with similar histological features and surrounding hepatic tissue was normal.

There were no postoperative complications and tumor markers returned to normal values. Adjuvant chemotherapy was decided after a CT scan reference evaluation that showed six residual hepatic metastases. The patient received 12 cycles of 5 -fluorouracil $\left(400 \mathrm{mg} / \mathrm{m}^{2} /\right.$ day for 5 days $)$ combined with streptozotocin ( $500 \mathrm{mg} / \mathrm{m}^{2} /$ day for 5 days) with good tolerance. At evaluation, there was a regression of the hepatic metastasis exceeding $30 \%$. Chemotherapy was stopped and then followed by lanreotide administration (one intramuscular injection of $30 \mathrm{mg}$ every 10 days) during 12 months, with the aim of controlling both recurrent hormonal hypersecretion and tumor growth. The patient did not report any symptoms, particularly no flushing or diarrhea, and physical examination was normal; lanreotide was stopped in 1994. CT scan and magnetic resonance imaging follow-up showed six stable tumors in the right liver. Tumor markers remained at a normal level. Between 1994 and 2000, the patient was followed every 6 months. A watery diarrhea appeared in 2000 , associated with pelvic pain without flushing. At abdominal palpation there was a mass located in the left hypogastric area, also found at vaginal touch. Tumor markers had increased (urinary 5HIAA $21 \mathrm{~N}$, chromogranin-A $74 \mathrm{~N}$ ). Somatostatin receptor scintigraphy showed uptake in the remaining liver, the peritoneum and the pelvic region, corresponding to metachronous metastasis of the left 
ovary. A hysterectomy with bilateral ovariectomy was performed. Pathological examination showed a diffuse metastatic invasion of both right and left ovaries, measuring respectively 40 and $130 \mathrm{~mm}$ in diameter. The residual tumor consisted in PC and metastases located in the right and residual left liver. Postoperatively, tumor markers decreased (urinary 5HIAA $5 \mathrm{~N}$, chromogranin-A $5 \mathrm{~N}$ ). Abdominal CT scan showed stable liver lesions.

In 2002, the patient complained of asthenia with a loss of $10 \mathrm{~kg}$ in 6 months, diarrhea and abdominal pain suggesting König's syndrome. Biological markers were as follows: urinary 5HIAA $15 \mathrm{~N}$, chromogranin-A $14 \mathrm{~N}$. A CT scan confirmed a $30 \%$ progression of liver metastases according to the RECIST criteria. Eight cycles of a second-line chemotherapy combining doxorubicin $\left(60 \mathrm{mg} / \mathrm{m}^{2} /\right.$ day) and dacarbazine $\left(150 \mathrm{mg} / \mathrm{m}^{2} /\right.$ day $)$ were administered between March 2002 and January 2003. Ankle and leg edema with distended jugular veins were noted, suggesting right heart failure. A tricuspid murmur was heard at cardiac auscultation. Transthoracic cardiac ultrasonography showed a stage IV carcinoid tricuspid valve insufficiency. The right cavities were dilated with moderate reflux in the inferior cava vein, pulmonary arterial pressure was $38 \mathrm{~mm} \mathrm{Hg}$ and left ventricular ejection fraction was $57 \%$ (cardiac ultrasonography had been normal in 2000). Somatostatin $(200 \mu \mathrm{g} \times 3$ per day, subcutaneous $)$ was then given and led to clinical improvement. Tumor burden remained stable. In July 2004, an acute deterioration of her terminal right heart failure occurred and the patient died, 13 years after initial diagnosis of the digestive NET with PC.

\section{Discussion}

Peritoneal involvement is uncommon in digestive NETs, including welldifferentiated midgut NETs, and data about its prevalence, prognostic signification and management are scarce. PC is less common in digestive NETs than in adenocarcinomas and occurs more frequently in NETs of midgut origin than in those of gastropancreatic (foregut) origin $[6,11]$. CT scan likely has insufficient sensitivity for diagnosis, and data about the prevalence of PC come from surgical series. Recently, the ENETS consensus guidelines for the management of peritoneal carcinomatosis from neuroendocrine tumors [12] have reported a $13 \%$ prevalence of PC in patients with midgut NETs at the time of diagnosis. The prevalence of PC seems to be higher (19-33\%) in well-differentiated NETs [1,11-13]. Ileal location of the primary tumor and liver dissemination are associated with the presence of PC. A gravity PC score (table 1) has been recently proposed to evaluate the importance of intra-abdominal metastatic diffusion [12]. Based on Gilly's classification (table 2), it quantifies preoperatively the extent of the disease within each region of the abdomen and pelvis, and includes the grading of lymph nodes and liver metastases.

The influence of peritoneal involvement in the survival of patients with NETs is unclear. Our group previously reported a series of 116 cases of digestive NETs, including 30 midgut NETs [11]. PC was present in 11 patients (10\%): 8 of the 30 midgut tumors and 3 from non-gastrinoma pancreatic tumors. In patients with midgut well-differentiated NETs, 5-year survival rates were 64 and $76 \%$ in patients with and without PC, respectively ( $p>0.05)$. Similarly, Boudreaux et al. [14] reported 4-year actuarial survival rates of 44 and $61 \%$ in patients with and without PC, respectively $(p=0.15)$. Whereas statistical significance was not reached in these two studies possibly due to a limited number of patients, it is not excluded that PC could be an independent pejorative prognostic factor in digestive NETs.

The management of PC in midgut well-differentiated NETs is not consensual. Whereas diffuse adenocarcinomatous PC is usually considered as a contraindication for surgical resection, the better prognosis of digestive NETs should make us 
systematically consider surgery as a therapeutic option. Aggressive surgical resections of the peritoneal involvement are under evaluation. Boudreaux et al. [14] reported a series of 82 advanced-stage NET patients who underwent a surgical procedure to determine the extent of disease and perform debulking. Peritoneal extension was present in $47.6 \%$. Debulking hepatic or other visceral metastases by resection, radiofrequency ablation, or combination led to improvement of symptoms in $91.5 \%$ of patients, and overall 4-year actuarial survival was 55\%. Elias et al. [13] reported 5-year survival rates of 40.9 and $66.2 \%$ in 20 patients undergoing a resection of PC for bowel obstruction, and in 17 patients undergoing 'maximal' cytoreductive surgery followed by immediate intraperitoneal chemotherapy with various combinations of mitomycin $\mathrm{C}$, 5 -fluorouracil, oxaliplatin and irinotecan, respectively $(p=0.007)$. In our observation, we used somatostatin analogs to slow tumor progression, as recently documented in the PROMID study [15], which showed a 67\% reduction in the risk of disease progression with octreotide LAR versus placebo. This study suggested that octreotide LAR might be considered as a treatment option in patients with well-differentiated midgut NETs and limited liver tumor burden $(\leq 10 \%)$.

Whereas PC in adenocarcinomas leads to many symptoms and complications, such as abdominal pain, ascitis and bowel obstruction, these symptoms seem to be unusual in patients with well-differentiated midgut NETs. Our group previously reported that life expectancy was not affected by PC [11]. In contrast, carcinoid heart disease is a major prognostic factor, whose specific management could significantly improve both survival and patient's quality of life. Carcinoid heart disease can be found in about $50 \%$ of patients with carcinoid syndrome, but it is symptomatic in only $10 \%$ [16]. Performing a cardiac ultrasound is thus justified in all patients with NETs and serotonin secretion, even if the carcinoid syndrome is incomplete [17]. Surgical replacement of the tricuspid valve should be discussed in case of symptomatic and severe right heart failure.

In conclusion, the presence of PC does not seem to impair survival by itself. It should not be considered as a contraindication for aggressive therapeutic strategy, such as extended loco-regional surgical resection of the tumor, hepatic metastases and carcinomatosis nodules. Whether combining aggressive surgery with chemotherapy (systemic/intraperitoneal) might improve overall survival and progression-free survival in these patients warrants further studies. Finally, targeted biotherapies such as sunitinib and everolimus, which have shown anti-tumor activity in pancreatic NETs $[18,19]$, should be further evaluated in unresectable well-differentiated metastatic NETs of midgut origin. 
Table 1. ENETS gravity PC grading system based on the association of PC with lymph node and liver metastases [12]

\begin{tabular}{lllll}
\hline & 0 points & 1 point & 2 points & 3 points \\
\hline $\begin{array}{l}\text { Lymph node } \\
\text { metastases }\end{array}$ & local (primary tumor relay) & $\begin{array}{l}\text { regional (secondary tumor } \\
\text { drainage territory relay) }\end{array}$ & $\begin{array}{l}\text { distant abdominal (hepatic } \\
\text { pedicle, retroperitoneal) }\end{array}$ & extra-abdominal \\
\hline $\begin{array}{l}\text { Liver } \\
\text { metastases }\end{array}$ & no macroscopic nodule & $\begin{array}{l}\text { one lobe } \\
<5 \text { nodules }\end{array}$ & $\begin{array}{l}\text { both lobes } \\
5-10 \text { nodules }\end{array}$ & $\begin{array}{l}\text { both lobes } \\
>10 \text { nodules }\end{array}$ \\
\hline PC & no macroscopic nodule & Gilly I-II resectable & Gilly III-IV resectable & Gilly unresectable \\
\hline
\end{tabular}

Grade A: 0-3 points; grade B: 4-6 points; grade C: 7-9 points.

Table 2. Gilly's classification based on nodule size and simplified extent of intraperitoneal dissemination [12]

$\begin{array}{ll}\text { Stage } 0 & \text { no macroscopic disease } \\ \text { Stage I } & \text { malignant granulations }<5 \mathrm{~mm} \text { in diameter localized in one part of the abdomen } \\ \text { Stage II } & \text { malignant granulations }<5 \mathrm{~mm} \text { in diameter diffuse to the whole abdomen } \\ \text { Stage III } & \text { localized or diffuse malignant granulations } 5-20 \mathrm{~mm} \text { in diameter } \\ \text { Stage IV } & \text { localized or diffuse large malignant masses }(>2 \mathrm{~cm} \text { in diameter })\end{array}$

\section{References}

1 Modlin IM, Lye KD, Kidd M: A 5-decade analysis of 13,715 carcinoid tumors. Cancer 2003;97:934-959.

2 Modlin IM, Oberg K, Chung DC, et al: Gastroenteropancreatic neuroendocrine tumours. Lancet Oncol 2008;9:61-72.

-3 Shebani KO, Souba WW, Finkelstein DM, et al: Prognosis and survival in patients with gastrointestinal tract carcinoid tumors. Ann Surg 1999;229:815-821.

-4 Janson ET, Holmberg L, Stridsberg M, et al: Carcinoid tumors: analysis of prognostic factors and survival in 301 patients from a referral center. Ann Oncol 1997;8:685-690.

5 Burke AP, Thomas RM, Elsayed AM, Sobin LH: Carcinoids of the jejunum and ileum: an immunohistochemical and clinicopathologic study of 167 cases. Cancer 1997;79:1086-1093.

6 Jann H, Roll S, Couvelard A, et al: Neuroendocrine tumors of midgut and hindgut origin: tumor-nodemetastasis classification determines clinical outcome. Cancer 2011;117:3332-3341.

7 Rindi G, Klöppel G, Couvelard A, et al: TNM staging of midgut and hindgut (neuro) endocrine tumors: a consensus proposal including a grading system. Virchows Arch 2007;451:757-762.

8 UICC; Sobin L, Gospodarowicz M, Wittekind C (eds): TNM Classification of Malignant Tumours, ed 7. Chichester, Wiley-Blackwell, 2009, 310 pp.

9 Rindi G, Arnold R, Bosman FT, et al: Nomenclature and classification of neuroendocrine neoplasms of the digestive system; in Bosman FT, Carneiro F, Hruban RH, Theise D (eds): WHO Classification of Tumours of the Digestive System. Lyon, International Agency for Research on Cancer, 2010, pp 13-14.

10 Yantiss RK, Odze RD, Farraye FA, Rosenberg AE: Solitary versus multiple carcinoid tumours of the ileum: a clinical and pathologic review of 68 cases. Am J Surg Pathol 2003;27:811-817.

11 Vasseur B, Cadiot G, Zins M, et al: Peritoneal carcinomatosis in patients with digestive endocrine tumors. Cancer 1996;78:1686-1692.

12 Kianmanesh R, Ruszniewski P, Rindi G, et al: ENETS consensus guidelines for the management of peritoneal carcinomatosis from neuroendocrine tumors. Neuroendocrinology 2010;91:333-340. 
13 Elias D, Sideris L, Liberale G, et al: Surgical treatment of peritoneal carcinomatosis from welldifferentiated digestive endocrine carcinomas. Surgery 2005;137:411-416.

14 Boudreaux JP, Putty B, Frey DJ, et al: Surgical treatment of advanced-stage carcinoid tumors: lessons learned. Ann Surg 2005;241:839-845.

15 Rinke A, Müller HH, Schade-Brittinger C, et al: Placebo-controlled, double-blind, prospective randomized study on the effect of octreotide LAR in the control of tumor growth in patients with metastatic neuroendocrine midgut tumors: a report from the PROMID Study Group. J Clin Oncol 2009;27:4656-4663.

16 Fox DJ, Khattar RS: Carcinoid heart disease: presentation, diagnosis, and management. Heart 2004;90:1224-1228.

17 Mansencal N, Mitry E, Bachet JB, Rougier P, Dubourg O: Echocardiographic follow-up of treated patients with carcinoid syndrome. Am J Cardiol 2010;105:1588-1591.

18 Raymond E, Dahan L, Raoul JL, et al: Sunitinib malate for the treatment of pancreatic neuroendocrine tumors. N Engl J Med 2011;364:501-513.

19 Yao JC, Shah MH, Ito T, et al: Everolimus for advanced pancreatic neuroendocrine tumors. N Engl J Med 2011;364:514-523. 